\title{
The Influence of Political Ideology and Socioeconomic Vulnerability on Perceived Health Risks of Heat Waves in the Context of Climate Change
}

\author{
MAtThew J. CUtLeR AND JENNIFER R. MARLON \\ School of Forestry and Environmental Studies, Yale University, New Haven, Connecticut \\ PETER D. HOWE \\ Department of Environment and Society, Utah State University, Logan, Utah \\ ANTHONY LEISEROWITZ \\ School of Forestry and Environmental Studies, Yale University, New Haven, Connecticut
}

(Manuscript received 11 October 2017, in final form 7 August 2018)

\begin{abstract}
Vulnerability and resilience to extreme weather hazards are a function of diverse physical, social, and psychological factors. Previous research has focused on individual factors that influence public perceptions of hazards, such as politics, ideology, and cultural worldviews, as well as on socioeconomic and demographic factors that affect geographically based vulnerability, environmental justice, and community resilience. Few studies have investigated individual socioeconomic and racial/ethnic differences in public risk perceptions of the health hazards associated with extreme heat events, which are now increasing due to climate change. This study uses multilevel statistical modeling to investigate individual- and geographic-level (e.g., census tract level and regional) social, economic, and biophysical influences on public perceptions of the adverse health impacts associated with heat waves. Political orientation and climate change beliefs are the strongest predictors of heat wave health risk perceptions; household income also has a relatively strong and consistent effect. Contextual socioeconomic vulnerability, measured with a social vulnerability index at the census tract level, also significantly affects heat wave risk perceptions. The strong influence of political orientation and climate beliefs on perceptions of adverse health impacts from heat waves suggests that ideological predispositions can increase vulnerability to climate change.
\end{abstract}

\section{Introduction}

Heat is the leading cause of weather-related mortality in the United States and is a hazard with which much of the population has direct experience (Borden and Cutter 2008). Recent research suggests that individuals in areas of greater social vulnerability more often perceive heat wave health risks, holding constant political attitudes and beliefs about climate change (Akerlof et al. 2015). Heat is a health hazard that is expected to increase in frequency and intensity as the climate continues to warm (IPCC 2014). Public perception of climate change, including the causes, consequences, and associated risks to human health and well-being, has been investigated across multiple social and behavioral

\footnotetext{
Corresponding author: Matthew J. Cutler, matthew.cutler@yale. edu
}

science disciplines (Swim et al. 2009, 2011; Dunlap and Brulle 2015). One of the persistent challenges, however, has been to identify the effects (if any) that physical changes to the environment (e.g., weather, plant and animal life, pollution) and geographically based sociodemographic factors (e.g., geographically based social vulnerability) have on public perceptions of climate change and its consequences. To design more effective communication strategies to reduce heat-related illness and injury, it will be vital for local, regional, and national organizations and agencies to develop a comprehensive understanding of the factors that shape public perceptions of the health risks posed by heat waves.

A key hurdle in this challenge, however, is that individual-level political attitudes and beliefs about environmental issues, such as climate change, may influence risk perceptions as much or more than sociodemographic and physical environmental factors, thus amplifying 
individuals' vulnerabilities. Therefore, ideological predispositions and beliefs and attitudes about climate change can be considered vulnerability factors alongside sociodemographic vulnerability. This study combines insights from the literatures on social vulnerability and public beliefs and attitudes about climate change in order to investigate the individual- and geographic-level sociodemographic and biophysical factors that may influence individuals' perceptions of the health risks associated with heat waves.

Part of the challenge in answering how environmental changes might affect public perceptions of risks stems from the diverse methodological approaches used by various scientific disciplines and traditions attempting to unpack this question. Social scientists have increasingly turned to the integration of biophysical and social survey data to include objective measures of environmental phenomena, such as floods, temperature trends, and other weather events, alongside individual-level sociodemographic predictors of public attitudes and perceptions (Egan and Mullin 2012; Goebbert et al. 2012; Howe et al. 2013; Hamilton and Lemcke-Stampone 2014; Zaval et al. 2014; Hamilton et al. 2016; Shao et al. 2017, 2018). In parallel, geographers have investigated the links between spatially concentrated vulnerabilities (e.g., clustering of multiple socioeconomic disadvantages) at different geographic levels (e.g., state, county, census tract, block group) and specific environmental hazards, in the case of floods, extreme heat, and disaster declarations (Cutter et al. 2003; Johnson et al. 2012). As a result of largely nonoverlapping research aims, these different literatures have left open questions that correspond with and could potentially be answered by each other's best insights. For example, individual-level beliefs and attitudes are embedded in geographically specific social and economic structures that condition their character to some degree. Geographically based vulnerabilities (i.e., socioeconomic characteristics of communities at various geographic levels such as census tracts or block groups) may also condition individual-level perceptions of risks due to increased exposure to hazards.

Specifically, this research explores four interrelated questions about individuals' perceptions of the risks heat waves pose to their own health and the health of others in their communities:

1) How might individuals' political ideologies and beliefs about the reality and causes of climate change influence their perceptions of the risks posed by heat waves to themselves and others within their communities?

2) How might individual-level sociodemographic characteristics relate to individuals' perceptions about the risks heat waves pose to their own health and the health of those around them?

3) How might geographic-level socioeconomic characteristics influence such perceptions?

4) How might objectively measured exposure to local heat waves influence such perceptions and net of individual- and geographic-level social and economic factors?

\section{Literature review}

\section{a. Background}

Recent research suggests that while the public is generally aware that climate change poses risks to human health, this awareness lacks specificity and is relatively shallow. A 2014 national survey compared respondents' answers to both open- and closed-ended survey questions about human health risks related to climate change and found that although the majority of the public said climate change will be harmful to human health, only about one-quarter were able to identify one or more specific types of harm (Maibach et al. 2015). Perhaps more importantly, most Americans responded by saying they had given little thought to the potential health consequences of climate change (Leiserowitz et al. 2014), suggesting that climate change impacts on local weather and extreme events have either not resonated with individuals in their everyday lives, or the majority of communities in America have simply not yet noticed the impacts of a changing climate. Alternatively (or in addition), it could be that Americans continue to see climate change as a relatively distant threat that poses more harm to people in developing nations or to future generations than to themselves, to their family and friends, or to others in their communities (Leiserowitz 2005; Akerlof et al. 2010; Leiserowitz et al. 2017). Since most of the public does not view climate change as a significant personal health risk, climate-related hazards may pose an even greater health threat in the near future if people inadequately prepare for or respond to the increasing risks. A deeper understanding of the particular social factors that influence public concern about heat wave health risks will be critical for organizations working to conduct effective communication campaigns to prevent or reduce heat-related health impacts. Whether and to what extent individuals perceive their own relative vulnerabilities is an important factor for policymakers and organizations involved in disaster preparation and response to consider.

\section{b. Individual-level influences on risk perceptions}

Though there has been much research on beliefs, attitudes, and risk perceptions related to climate change, 
the majority of studies have focused on identifying and explaining what Van Liere and Dunlap (1980) referred to as the "social bases of environmental concern." From the "age, social class, residence, political, and sex hypotheses" (see Van Liere and Dunlap 1980) emerged myriad studies over the following decades charting the sociodemographic correlates of individual beliefs, attitudes, perceptions of risks, and norms of behavior with respect to environmental issues and problems-most notably, in recent years, the social and political dimensions of climate change beliefs. In addition to individual-level sociodemographic indicators, some of which are meant to capture individual-level vulnerability, this study also considers the influence of political ideology and global warming beliefs on heat wave health risk perceptions. Many studies have shown a consistent and relatively strong effect of political views on beliefs and concerns about environmental issues, especially the issue of climate change (Leiserowitz 2005; Hamilton 2008; Hamilton et al. 2012; McCright 2011; McCright et al. 2014; Marquart-Pyatt et al. 2014). Additionally, beliefs about the reality and cause of climate change have been shown to influence perceptions of local temperature and weather patterns (Cutler 2015, 2016; Howe and Leiserowitz 2013; Howe 2018).

At the same time, a rich literature has emerged demonstrating that racial and ethnic minorities are often more vulnerable to environmental hazards (Bullard and Johnson 2000; Cutter et al. 2003; Brulle and Pellow 2006; Klinenberg 2015; Bolin and Kurtz 2018) and demonstrating individual and geographically based influences on risk perceptions of hazards (e.g., White 1945; Kates 1962; Kasperson and Dow 1993; Slovic 1993; Hamilton and Keim 2009; Marlon et al. 2018). There have been relatively few studies, however, that focus on racial and ethnic differences in heat wave risk perceptions as a characteristic of individual-level vulnerability. More broadly, there have been several studies documenting a "white male" and "conservative white male effect" of relatively low-risk perceptions across a variety of hazards (Finucane et al. 2000; Kahan et al. 2007; McCright and Dunlap 2013).

Among other sociodemographic correlates, older age has been associated with increased risk for adverse health consequences of extreme heat exposure, in addition to other hazards (Reid et al. 2009; Johnson et al. 2012; Klinenberg 2015; Gronlund et al. 2016). But risk perception studies have not found older age to be associated with increased risk perceptions of climate change (Leiserowitz 2006; Akerlof et al. 2015). While age is a factor in vulnerability to heat, older people do not appear to be more likely to view themselves as at increased risk for heat-related health problems, perhaps in part because they often do not perceive themselves to be "old" (Abrahamson et al. 2009). As referenced above, men tend to have lower perceptions of risks associated with environmental hazards, but women also tend to express greater concern about environmental issues more generally (Dunlap and Van Liere 1984; Stern et al. 1993; Stern and Dietz 1994; Dietz et al. 2005), as well as the impacts of climate change specifically (Hamilton 2008; Hamilton and Keim 2009; McCright 2010; Goebbert et al. 2012).

Educational attainment typically exerts a direct influence on concern about environmental issues, such that more educated individuals tend to express greater concerns or risk perceptions (Dunlap and Van Liere 1984; Jones and Dunlap 1992). Education and scientific literacy, however, also interact with politics, such that higher educational attainment among self-identified Republicans or political conservatives corresponds to lower perceived risks and less concern about environmental issues, which may indicate motivated reasoning (Hamilton 2008; Hamilton et al. 2012; Hamilton and Saito 2015; McCright and Dunlap 2011; McCright 2011; Krosnick et al. 2000; Malka et al. 2009; Shao et al. 2014).

Finally, lower household income at the individual level is associated with increased perceived local impacts of climate change and related environmental phenomena (Hamilton and Keim 2009; Cutler 2015, 2016; Shao et al. 2016, 2014). In fact, recent research has shown a multiplicative effect of household income and local property damage from severe weather on perceptions of extreme weather events and the threat of climate change, such that individuals living in low-income households in the most heavily impacted places express greater awareness of and concern about personal risk and property damage from severe weather events (Cutler 2015, 2016). Income has often been incorporated in broader indices intended to capture social vulnerability to environmental hazards, but such studies generally utilize geographically based measures of income, such as median or per capita household income aggregated to subregion or substate geographic areas (Cutter et al. 2003; Cutter and Finch 2008; Johnson et al. 2012; Boruff et al. 2005; Wood et al. 2010). There have been very few, if any, prior attempts to look at both individual household income and broader geographical area income together in studies of perceptions of environmental hazards. The advantage of this approach is that it can capture the possible effect of socioeconomic context at the geographic level on individual-level perceptions of vulnerability. Variables associated with social context at the geographic level (i.e., employment structure, community characteristics, levels of social trust and altruism) have been identified as important predictors of 
public beliefs, attitudes, and perceptions about social and environmental issues (Hamilton et al. 2010; Safford et al. 2012; Sampson 2012). This study addresses a critical gap in the literature by specifically investigating whether geographically based socioeconomic context matters to individual perceptions of personal and community vulnerability to heat waves, an increasingly important public health concern.

\section{c. Geographic and biophysical influences on risk perceptions}

While much of the prior literature has focused on individual-level factors as predictors of environmental attitudes and risk perceptions in general, less attention has focused specifically on the socioeconomic and demographic influences on heat wave risk perceptions, especially the potential geographic-level socioeconomic factors that can put some individuals in positions of increased risk for harm. Perceptions are an important determinant of responses to risks, so an improved understanding of the drivers of risk perceptions can clarify how climate change impacts may affect individuals and populations (Leiserowitz 2005; Thomas et al. 2007; Whitmarsh 2008; Weber 2010; Wilhelmi and Hayden 2010).

The human dynamics of hazards can be conceptualized through the lens of social vulnerability, which has been defined as "...the sensitivity of a population to natural hazards and its ability to respond to and recover from the impacts of hazards" (Cutter and Finch 2008). Using county-level socioeconomic and demographic data, Cutter et al. (2003) constructed one of the first comprehensive measures of social vulnerability to environmental hazards, the social vulnerability index (SoVI). The SoVI combined factors related to personal wealth, age, density of the built environment, singlesector economic dependence, housing stock and tenancy, race, ethnicity, occupation, and a hybrid construct comprising employment in infrastructure and local debtto-revenue ratios (Cutter et al. 2003).

SoVI has since been utilized extensively to map and analyze vulnerability at various scales and over various periods of time (Boruff et al. 2005; Cutter et al. 2006; Cutter and Emrich 2006; Boruff and Cutter 2007; Cutter and Finch 2008; Wood et al. 2010) and has also been adapted to include other measures of vulnerability, including actual heat exposure through the incorporation of land surface temperature data (Johnson et al. 2012). Reid et al. (2009) specifically mapped heat-related vulnerability (but not perceptions of vulnerability) in urban census tracts across the United States using an approach similar to Cutter et al. (2003); they identified four types of vulnerability factors, including social/environmental variables (e.g., education and poverty), social isolation, lack of air conditioning, and proportion of elderly with diabetes.

While SoVI and related indicators have helped explain geographic variation in environmental hazards vulnerability, they also have the potential to serve as important predictors of perceptions of vulnerability to environmental hazards, especially heat waves. Where studies have documented the link between actual and perceived vulnerabilities, they have found that particularly vulnerable populations, such as racial and ethnic minorities, are more likely to perceive risks from environmental hazards (Akerlof et al. 2015). However, this link between perceived and actual vulnerabilities to environmental hazards has also been relatively underexplored (Brody et al. 2008; Wolf et al. 2010; Spence et al. 2011). Perceptions of risks have been analyzed as correlates of personal values, worldviews, and other culturally rooted cognitive processes at the individual level, but geographically based factors and, specifically, social vulnerability have received less attention, perhaps due to a lack of data availability at various spatial and geographic units and/or because relevant social-psychological theories of environmental attitudes and risk perceptions tend to focus on individuals rather than geographic areas as their units of analysis. Yet, individuallevel values are often embedded in geographically specific contexts and connected to locally relevant phenomena, such as cultural milieu, history, economic vibrancy, and patterns of integration or segregation, among other factors (Guagnano and Markee 1995; Kitchin et al. 1997; Lorenzoni and Pidgeon 2006; Shwom et al. 2008; Hamilton and Keim 2009; Hamilton et al. 2010; Safford et al. 2012; Sampson 2012; Chuang et al. 2013; Hamilton and Safford 2015).

Local weather and climate-including temperature and humidity - are another set of geographically based factors that may influence heat wave health risk perceptions. Several recent studies document linkages between observational weather and climate data and public perceptions of those events in the context of anthropogenic climate change. Using 2012 national survey data, Howe et al. (2014) overlaid public perceptions and reported personal experience with hurricanes, tornadoes, and drought onto maps of observed impacts from each of the three event types and found that personal experience corresponds well with the geographic distribution of reported impacts, particularly for hurricanes and tornadoes.

Event trends have also been included in models predicting perceptions of weather events. Goebbert et al. (2012) used trends in temperature and the Palmer drought severity index (PDSI) by zip code with individual-level sociodemographic information from a national survey to analyze local climate perceptions. Perceptions of temperature were not significantly associated with actual changes 
in the weather, but respondents who lived in areas with higher 3-yr-average departures in the PDSI from the 30-yr average were more likely to perceive local flooding and drought (Goebbert et al. 2012). Other research suggests that trends in local temperatures, both in the United States and cross nationally, correspond with perceptions of local warming specifically (Hamilton and Keim 2009; Howe et al. 2013; Howe and Leiserowitz 2013) and beliefs about climate change more generally (Myers et al. 2013; Egan and Mullin 2012; Hamilton and Stampone 2013; Hamilton and Lemcke-Stampone 2014; Shao 2016; Shao et al. 2016). Evidence for a recency bias has also been demonstrated through research on perceptions of changes in hurricane strength, consistent with research showing that recent experiences may be more influential to perceptions than trends over time (Weber 2010; Shao et al. 2016).

There have also been efforts to incorporate data on weather extremes in studies of public perceptions of weather events and climate change, but little consensus has been achieved as to which events affect perceptions most or which measures are most useful. Brody et al. (2008) examined several different factors related to extreme weather vulnerabilities, including economic and property damages, injuries, fatalities, and fires, and found that the number of fatalities and economic damages in excess of $\$ 1$ billion was associated with perceptions of personal and local risks from climate change. Yet, Marquart-Pyatt et al. (2014) used the National Oceanic and Atmospheric Administration's (NOAA) Climate Extremes Index (CEI) and found that the regional-level measure did not significantly predict public beliefs about the seriousness and timing of climate change impacts net of political identity and other sociodemographic factors. Similarly, Brulle et al. (2012) did not find any significant relationship between NOAA's CEI at the national level and a "climate change threat index" constructed from multiple survey items intended to measure aggregate U.S. national opinion about the threat posed by climate change. Shao and Goidel (2016) also demonstrated that political orientation is the primary driver of perceptions of local weather conditions, and in turn, those perceptions overshadow objective weather conditions in influencing attitudes about climate. While studies utilizing survey research on public opinion about climate change have often included biophysical factors, many lack finescale geographic data to identify specific impacts within respondents' own areas. A key component missing from all of these studies is a focus on public perceptions of the health risks associated with climate and weather extremes, especially in the context of social and physical vulnerabilities.

This research investigates four interrelated hypotheses based on the theoretical insights from the prior literature on climate change risk perceptions and the geographically varying social and physical conditions related to environmental hazards vulnerabilities. First, we expect individual ideological orientations and beliefs about climate change to exert the largest influence over perceptions of the health risks associated with heat waves, such that conservatives who are skeptical about the reality and cause of climate change will be much less likely to perceive health risks from heat waves than liberals who believe climate change is real and human caused. Second, we expect that individual-level socioeconomic factors, such as race/ethnicity, income, age, and gender, will all exert significant influences on heat wave health risk perceptions net of ideological factors. Third, we expect that geographically based socioeconomic factors associated with hazards vulnerability will exert some level of influence on individual-level risk perceptions, such that those living in more socioeconomically vulnerable places will perceive greater risks from heat waves. Finally, we expect to find a relationship between observed heat conditions and perceptions of risks, such that those living in areas more heavily impacted by extreme heat conditions will be more likely to perceive health risks and net of social and ideological factors.

\section{Methods}

\section{a. Sample}

This study utilizes two waves of the biannual, nationally representative Climate Change in the American Mind (CCAM) surveys, conducted by the Yale Program on Climate Change Communication and the Center for Climate Change Communication at George Mason University. The CCAM surveys have tracked public beliefs and attitudes about climate change and a wide range of associated issues and topical areas, such as risk perceptions, media consumption habits, policy preferences, and many others (Leiserowitz et al. 2018). There have been 18 waves of CCAM data collected since fall 2008. While some items have been tracked throughout CCAM's deployment, most survey questions have been asked more selectively. This research uses two of the 18 waves wherein the survey items that serve as the dependent variables were assessed. Descriptive information, including sample size and data collection dates, for each wave is provided in Table 1. Samples were drawn from GfK's KnowledgePanel, an online panel of members recruited using probability sampling via random digit dialing and address-based mail techniques that cover essentially all resident phone numbers and mail addresses in the United States. Survey questionnaires were self-administered by respondents through a webbased environment. Those sampled who chose to join the panel but did not have access to the internet at home 
TABLE 1. Independent variables from CCAM surveys.

\begin{tabular}{|c|c|c|c|}
\hline Variable & Range & Mean (standard deviation) & $N$ \\
\hline \multicolumn{4}{|c|}{ Individual-level characteristics } \\
\hline Age & $1(18-29), 2(30-44), 3(45-59), 4(60+)$ & $2.856(1.072)$ & 2556 \\
\hline Gender & 0 (male), 1 (female) & $0.517(0.500)$ & 2556 \\
\hline Education & $\begin{array}{l}1 \text { ( }<\text { high school), } 2 \text { (high school), } 3 \\
\quad \text { (some college), } 4 \text { (Bachelor's or higher) }\end{array}$ & $2.933(0.968)$ & 2556 \\
\hline Household income & $\begin{array}{c}1(<\$ 25,000), 2(\$ 25,000-\$ 34,999), 3 \\
(\$ 35,000-\$ 49,999), 4(\$ 50,000-\$ 74,999) \\
5(\$ 75,000-\$ 99,999), 6(\$ 100,000+)\end{array}$ & $3.985(1.786)$ & 2556 \\
\hline Race/ethnicity & $\begin{array}{l}1 \text { (white, non-Hispanic), } 2 \text { (Hispanic), } \\
\quad 3 \text { (African American, non-Hispanic), } \\
\quad 4 \text { (other/multiracial) }\end{array}$ & - & 2556 \\
\hline Ideology & $\begin{array}{l}1 \text { (very liberal), } 2 \text { (somewhat liberal), } \\
3 \text { (moderate), } 4 \text { (somewhat } \\
\text { conservative), } 5 \text { (very conservative) }\end{array}$ & $3.129(1.075)$ & 2525 \\
\hline Global warming belief & $\begin{array}{l}1 \text { (human caused-reference category), } \\
2 \text { (natural), } 3 \text { (not happening), } \\
4 \text { (other belief/do not know) }\end{array}$ & - & 2555 \\
\hline Census division & $\begin{array}{l}\text { Census division and CCAM sur } \\
1 \text { (New England), } 2 \text { (Mid-Atlantic), } \\
3 \text { (East-North Central), } 4 \text { (West-North } \\
\text { Central), } 5 \text { (South Atlantic), } 6 \\
\text { (East-South Central), } 7 \text { (West-South } \\
\text { Central), } 8 \text { (Mountain), } 9 \text { (Pacific) }\end{array}$ & - & 2556 \\
\hline Survey wave & 0 (Nov 2016), 1 (Oct 2015) & $0.520(0.500)$ & 2556 \\
\hline
\end{tabular}

were loaned personal computers and provided with internet access in order to participate so that the web-based design would not systematically exclude certain segments of the population. Postsurvey weights were applied to demographic variables to match the U.S. Census Bureau's norms.

\section{b. Dependent variables}

This study analyzes individuals' perceptions of the impacts that a heat wave would have on their own personal health and the health of those in their communities. The dependent variables were constructed from two survey questions aimed at assessing respondents' perceptions about the extent to which a heat wave would have an impact on their own personal health or the health of those within their communities. These survey questions, ${ }^{1}$ assessed in the October $2015(n=1344)$ and November 2016 ( $n=1226)$ CCAM surveys, included a brief preface, "A heat wave is a period of unusually and uncomfortably hot weather," and then proceeded to ask respondents, "If a heat wave were to occur in your local area, how much, if at all, do you think it would harm the following," with reference to their own personal health

\footnotetext{
${ }^{1}$ The survey questions on risks of harm from heat waves came before the suite of questions on climate change beliefs and attitudes, thus eliminating the possibility of biasing responses in one direction.
}

and the health of others in their communities. Respondents were not provided with any higher level of specificity regarding how long the "period of unusually and uncomfortably hot weather" referred to, in part because subjective experience of heat waves may differ from technical definitions provided by agencies monitoring such events. Respondents were provided a slider bar with values on a scale from 0 to 100 and asked to use the slider to indicate "how much" a heat wave would impact each. The October 2015 and November 2016 waves of CCAM were the first in which these two items had been assessed. ${ }^{2}$

\section{c. Independent variables and individual-level vulnerability}

Independent variables at the individual level included diverse sociodemographic indicators, respondents' beliefs about global warming, and ideological identification. Census division of residence (based on the nine Census divisions ${ }^{3}$ ) and an indicator of survey wave

\footnotetext{
${ }^{2}$ Given that these surveys were the first time these items had been assessed, no prior knowledge had been generated about how individuals would tend to respond to the scale and slider bar format presented for this particular pair of questions.

${ }^{3}$ https://www2.census.gov/geo/pdfs/maps-data/maps/reference/ us_regdiv.pdf.
} 
TABLE 2. Geographically based vulnerability: 2014 ACS 5-yr census tract estimates.

\begin{tabular}{lccc}
\hline \multicolumn{1}{c}{ Variable } & Range & Mean (standard deviation) & \multicolumn{1}{c}{$N$} \\
\hline Percent nonwhite & $0-100$ & $20.23(21.21)$ & 2544 \\
Percent less than high school education & $0-100$ & $15.20(11.61)$ & 2539 \\
Median age & $15.8-78.2$ & $39.14(7.23)$ & 2542 \\
Median household income & $\$ 3,576-\$ 108,472$ & $\$ 30,809.61(\$ 11,862.11)$ & 2542 \\
Percent below poverty & $0-100$ & $14.06(11.33)$ & $14.45(19.16)$ \\
Percent Hispanic & $0-100$ & $4486.36(10888.63)$ & 2543 \\
Population density & $0-154454.9$ & $8.90(5.55)$ & 2544 \\
Unemployment rate & $0-100$ & & 2542 \\
\hline
\end{tabular}

participation were also included to account for spatial and temporal variability among survey respondents. All independent variables derived from CCAM survey data are described in Table 1. A categorical indicator for racial and ethnic identities was created from a five-category nominal variable that reported respondents' race or ethnicity. In addition to race and ethnicity, other sociodemographic indicators at the individual level included respondents' age, gender, education, and household income.

Finally, among individual-level predictors, this analysis included individuals' self-reported political ideology and beliefs about the reality and cause of global warming. Political ideology is treated as a five-category ordinal measure, from "very liberal" to "very conservative." The variable used to indicate global warming beliefs was derived from an original survey item that asked respondents whether they believed global warming is mostly due to 1) human causes, 2) natural changes in the environment, 3) neither because it is not happening, or 4) respondents could indicate that they were either unsure or had another belief about the cause of global warming. Human causation was treated as the reference category in the four-category nominal variable used in statistical models because initial bivariate analysis revealed this response option to have the greatest positive correlation with responses to the dependent variable, thus facilitating interpretation of the results.

\section{d. Geographically based vulnerability}

To capture the possible influence of geographically based social vulnerability on perceptions of heat wave risks, a proxy measure of vulnerability was utilized informed by the prior literature on SoVI and related indices (Cutter et al. 2003, 2008, 2010; Johnson et al. 2012; Schmidtlein et al. 2008). The variables used to construct the measure were derived from the 2014 American Community Survey's (ACS) 5-yr census tract estimates. These census tract data were matched to survey respondents utilizing jittered $( \pm 150 \mathrm{~m})$ coordinates for respondents' household addresses. The ACS variables used to construct this measure included the percentage of nonwhite residents, the percentage of residents with less than a high school education, median age, median household income, the percentage of residents below the federal poverty line, the percentage of Hispanic residents, population density, and the unemployment rate. The choice of this set of variables was primarily informed by Johnson et al.'s (2012, p. 25) extreme heat vulnerability index (EHVI). The sociodemographic variables utilized in our proxy measure cover the major components of EHVI, which accounted for about $73 \%$ of explained variance and included age, race/ethnicity, household income, education, and population density (Johnson et al. 2012). Table 2 displays descriptive information for each of the variables used to construct this proxy measure of heat vulnerability. Not only do these cover the major components of prior indices, including racial and ethnic composition, age structure, urban density, and socioeconomic status, but these variables are also considered among the most "prevalent indicators of vulnerability" in the context of extreme heat (Johnson et al. 2012). Standard scores ( $Z$ scores) were calculated for each variable prior to inclusion, and the entire set of $Z$ scores was summed to produce a single measure for each respondents' census tract. The Cronbach's alpha for the scale was 0.74 , indicating a sufficient degree of internal reliability. While Cronbach's alpha does not test for dimensionality as principal components analysis does, this set of variables was previously determined to represent three highly intercorrelated components of an index of extreme heat vulnerability (Johnson et al. 2012). A Cronbach's alpha of 0.74 is generally considered a high-degree shared covariance and likely demonstrates that this proxy measure indicates an underlying construct: geographically based social vulnerability.

\section{e. Biophysical variables}

Biophysical variables included in this study came from two derived measures of heat incidence and intensity: 1 ) cooling degree-days (CDD) and 2) the heat stress index (HSI). Data on CDD were obtained from NOAA's Climate Prediction Center (CPC). These data are provided at the level of the climate division, a substate 
TABLE 3. NWS cooling degree-days (CDDs) and heat stress index (HSI).

\begin{tabular}{|c|c|c|c|}
\hline Variable & Range & Mean (standard deviation) & $N$ \\
\hline \multicolumn{4}{|c|}{ May-Sep CDDs } \\
\hline 2015 CDD total & $85-2757$ & $1186.76(692.83)$ & 1321 \\
\hline 2015 CDD anomaly & $-484.61-319.82$ & $69.60(125.67)$ & 1321 \\
\hline 2016 CDD total & $49-2817$ & $1316.13(692.42)$ & 1210 \\
\hline 2016 CDD anomaly & $-456.61-550.70$ & $188.83(135.45)$ & 1210 \\
\hline \multicolumn{4}{|c|}{ May-Sep HSI } \\
\hline 2015 HSI total & $0-65$ & $23.29(13.14)$ & 1330 \\
\hline 2015 HSI anomaly & $-27.64-37$ & $7.11(10.84)$ & 1330 \\
\hline 2016 HSI total & $0-77$ & $28.82(13.37)$ & 1226 \\
\hline 2016 HSI anomaly & $-27.64-55.06$ & $12.39(11.17)$ & 1226 \\
\hline
\end{tabular}

geographic area. Descriptive statistics for the biophysical variables are provided in Table 3 . There are 344 climate divisions in the United States. Monthly temperature and precipitation values are computed from daily station observations in each division. According to NOAA's CPC, $\mathrm{CDD}$ are defined as "a quantitative index demonstrated to reflect demand for energy to. . . cool houses and businesses" and are the summation of positive differences between the mean daily temperature and a base of $65^{\circ} \mathrm{F}$. To illustrate how these data might look, the CPC provides the example that "cooling degree days for a station with daily mean temperatures during a 7-day period of $67,65,70,74,78,65$, and 68 are 2, 0, 5, 9, 13, 0 , and 3, for a total for the week of 32 cooling degree days." ${ }^{4}$ The CPC estimates degree-days for substate climate divisions and applies population weights to accurately estimate temperature-related energy consumption. The total CDD from the period of May-September prior to their survey completion date were merged with survey data according to each respondent's climate division. The warmest months were selected in order to control for the seasonal variability across the country that could lead to inflated estimates for portions of the country that experience warmth well before or after the summer months. To also capture the potentially important influence of abnormal May-September CDD, anomalies were calculated as the departure of the total CDD from the 19812013 averages by climate division for each respondent.

In addition to a measure of temperature-related energy use in warm months, this study incorporates a measure of apparent ambient temperature, or "how hot it feels" based on both temperature and humidity. The National Centers for Environmental Information (NCEI) at NOAA calculate an HSI using data on temperature and humidity from hourly observations by the 187 National Weather Service (NWS) stations across the

\footnotetext{
${ }^{4}$ http://www.cpc.ncep.noaa.gov/products/analysis_monitoring/ cdus/degree_days/ddayexp.shtml.
}

nation. These data are provided in the form of the average single-day exceedances above the 85 th percentile per month. ${ }^{5}$ In a similar fashion to the CDD, survey respondents were matched with the HSI for their local climate division for the months of May-September preceding the survey date. Anomalies were calculated to capture the departure from the 1981-2013 average HSI and included in statistical models.

While a number of recent studies suggest a link between temperature and weather and beliefs about climate change (e.g., Howe et al. 2014; Cutler 2016; Shao et al. 2016), other recent studies using measures of temperature trends, flooding events, and climate extremes do not find that such event types significantly predict public perceptions and beliefs about climate-related phenomena (Brody et al. 2008; Goebbert et al. 2012; Hamilton et al. 2016; MarquartPyatt et al. 2014). The novel approach of this study, however, is to use CDD and HSI as measures of the "felt impacts" of rising temperatures. Since CDDs are computed in reference to the point at which most people turn on air conditioning, fans, or other energy-consumptive cooling methods, higher average CDDs may capture the human impact of heat better than raw temperatures or anomalies. Likewise, HSI accounts for differences in humidity that affect how hot it feels, adding information to the absolute temperatures alone.

\section{f. Analytical strategy}

The distribution of responses on the continuous $0-100$ scale was multimodal, with substantial proportions of responses clustered below 20, between 20 and 40, between 40 and 60 , and above 60 . Therefore, the dependent variable was treated as ordered categorical, and ordered logistic regression was used to analyze the individual-level and geographically based influences on the outcome variable. This analytical choice may be

\footnotetext{
${ }^{5}$ https://www.ncdc.noaa.gov/societal-impacts/heat-stress/data.
} 
TABLE 4. Mixed-effects ordered logistic regressions of perceived health risks of heat waves on individual- and geographic-level characteristics (pooled Oct 2015 and Nov 2016 CCAM surveys). Significance level: * is $p<0.05, * *$ is $p<0.01$, *** is $p<0.001$.

\begin{tabular}{|c|c|c|}
\hline & Model 1: "My health" & $\begin{array}{l}\text { Model 2: "Health of others in my } \\
\text { community" }\end{array}$ \\
\hline Independent variables & Odds ratios ( $95 \%$ confidence $)$ & Odds ratio ( $95 \%$ confidence) \\
\hline \multicolumn{3}{|l|}{ Individual characteristics } \\
\hline Age & $1.170 * * *(1.092-1.254)$ & $1.138 * * *(1.057-1.214)$ \\
\hline Gender (female) & $1.189 *(1.025-1.379)$ & $1.310 * * *(1.133-1.515)$ \\
\hline Education & $0.821 * * *(0.755-0.893)$ & $0.914 *(0.839-0.994)$ \\
\hline Household income & $0.876^{* * *(0.836-0.917)}$ & $0.931 * *(0.890-0.975)$ \\
\hline Ideology (very liberal-very conservative) & $0.890 * *(0.823-0.961)$ & $0.826 * * *(0.765-0.892)$ \\
\hline Oct 2015 & $1.735 * * *(1.463-2.056)$ & $1.079(0.915-1.272)$ \\
\hline \multicolumn{3}{|l|}{ White, non-Hispanic } \\
\hline Hispanic & $1.309 *(1.032-1.662)$ & $1.150(0.885-1.493)$ \\
\hline African American & $1.406 * *(1.084-1.825)$ & $1.169(0.874-1.565)$ \\
\hline Other race/multiracial & $1.984 * * *(1.465-2.686)$ & $1.507 * *(1.114-2.040)$ \\
\hline \multicolumn{3}{|l|}{ Global warming belief (Human) } \\
\hline Natural & $0.624 * * *(0.526-0.740)$ & $0.521 * * *(0.440-0.617)$ \\
\hline Not happening & $0.281 * * *(0.203-0.390)$ & $0.235 * * *(0.170-0.326)$ \\
\hline Do not know & $0.418 * *(0.220-0.795)$ & $0.351 * *(0.180-0.684)$ \\
\hline Census division & ns & ns \\
\hline \multicolumn{3}{|l|}{ Place characteristics } \\
\hline Vulnerability index & $1.028 *(1.002-1.055)$ & $1.031 *(1.005-1.059)$ \\
\hline May-Sep 2015/16 CDD & $1.000(1.000-1.000)$ & $1.000(1.000-1.000)$ \\
\hline May-Sep 2015/16 CDD anomaly & $1.000(0.999-1.001)$ & $1.000(0.999-1.001)$ \\
\hline May-Sep 2015/16 HSI & $0.994(0.973-1.017)$ & $0.998(0.979-1.017)$ \\
\hline May-Sep 2015/16 HSI anomaly & $1.016(0.990-1.043)$ & $1.006(0.983-1.029)$ \\
\hline \multicolumn{3}{|l|}{ Random intercept } \\
\hline Climate division & 0.038 & 0.000 \\
\hline$N$ & 2477 & 2477 \\
\hline Cut $1 /$ Cut $2 /$ Cut 3 & $-1.457 /-0.200 / 1.092$ & $-2.280 /-0.759 / 0.830$ \\
\hline Wald chi $^{2}$ & $307.96^{* * *}$ & $279.76^{* * *}$ \\
\hline
\end{tabular}

limited in that it reduces the variability of responses to the dependent variable and may lose important information as a result, but given that roughly $20 \%-25 \%$ of respondents fell into each quarter of the $0-100$ scale, it was more appropriate to treat the variable as ordinal. Since geographic predictor variables are included in these statistical models, and survey responses may be spatially autocorrelated, the ordered logistic regressions were constructed as multilevel, mixed-effects models with climate division set as a second-level random effect.

\section{Findings}

Results from weighted, mixed-effects ordered logistic regressions of the individual- and geographic-level predictors on the dependent variables are reported in Table 4. Odds ratios reported are in reference to 1.0 , where positive effects are above 1.0, and negative effects are below 1.0. Positive odds ratios in Table 4 refer to the multiplicative effects on the odds of a "60-100" response on the heat wave harm slider bar for a unit increase in the predictor versus the lower three ordered categories of possible responses, " $0-20$," " $20-40$," or
"40-60," whereas negative ratios refer to the multiplicative effects on the odds of a " $0-20$ " response versus the combined "20-40," "40-60," and "60-100" categories. Indirect effects between all geographic- and individual-level variables were tested using a stepwise procedure and through the creation of interaction terms, but we did not find any significant results to indicate mediating or moderating influences of independent variables on the dependent variable. Therefore, results presented in Table 4 include only direct effects.

As hypothesized, political ideology and beliefs about global warming each consistently predict respondents' perceptions of the health risks from future heat waves. Conservatives perceive personal or community health risks from heat waves much less often than liberals. The odds of " $60-100$ " responses on the heat wave harm slider bars for personal or community health were $11 \%$ and $16 \%$ lower, respectively, with a unit increase in the ideology indicator. Beliefs about global warming also significantly predict heat wave health risk perceptions. Belief in any cause other than the human causation of global warming-including that global warming is a natural phenomenon, that it is not happening at all, or 


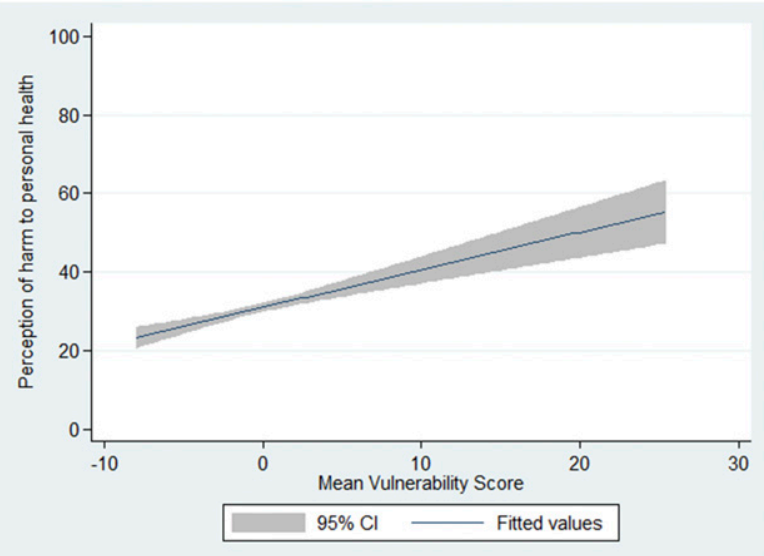

FIG. 1. Predicted individual perceptions of personal health risks of heat waves by geographic-level vulnerability.

being unsure or having any other unclassified viewpoint-results in much lower odds of reporting harm from heat waves to personal or community health. The belief that human-caused global warming is not happening, however, produces a much stronger negative effect on the odds of perceiving heat wave harm to either personal or community health. For example, the odds of a "60-100" response on the slider bars indicating harm to personal and community health are $72 \%$ and $74 \%$ lower, respectively, among those who believe global warming is not happening at all versus happening due to human causes, whereas the odds are $37 \%$ and $47 \%$ lower, respectively, among those who believe global warming is happening, but due to natural causes versus human causes.

In a similar fashion to ideology and global warming beliefs, we did find evidence for the second hypothesized relationship between individual-level sociodemographic factors and perceptions of heat wave health risks. Individual-level household incomes significantly predict perceptions of the risks posed by future heat waves net of other individual- and geographic-level variables. The odds of a "60-100" response on the slider bar to personal and community health decline by $12 \%$ and $7 \%$, respectively, for a single-unit increase in the six-point household income indicator. For example, the odds of a "heat wave would cause harm to my personal health" response are $47 \%$ lower among individuals in households with incomes greater than $\$ 100,000$ (U.S. dollars) annually $\left(0.88^{5}=0.53\right)$, compared to all other household income categories in the six-point scale and controlling for other variables. Thus, while ideological predispositions are persistent and relatively strong predictors of perceived harm from heat waves, individual-level vulnerability as measured through household income is also important. Educational attainment, another component of socioeconomic status, is a significant predictor for personal health risk perceptions. The odds of a "heat wave would cause harm" response or a " $60-100$ " response on the harm slider bar are $16 \%$ and $18 \%$ lower, respectively, for a unit increase in the four-point educational attainment indicator.

Respondents' age and racial/ethnic identities also predict perceptions of heat wave health risks. The odds of a " $60-100$ " response on the harm slider bars for personal and community health increase by $17 \%$ and $14 \%$, respectively, with a single-unit increase in the fourcategory age indicator. Racial and ethnic identities, on the other hand, have a more complex relationship to heat wave health risk perceptions. In general, nonwhite respondents are more likely than white respondents to perceive heat waves as a personal health risk, but community health risk perceptions are higher only among "other" (any race/ethnicity other than white, African American, or Hispanic) or multiracial respondents.

Among the hypothesized geographically based predictors, only socioeconomic vulnerability significantly predicts perceptions of heat wave health risks. Predicted values for personal health risk perceptions are plotted against the mean vulnerability score in Fig. 1. As reported in Table 1, the odds of responding " $60-100$ " on the slider bar for both personal and community health risks increase by $3 \%$ with a single-point increase in the vulnerability index, holding all other individual- and geographic-level predictors constant. On the other hand, none of the measures of "felt impacts" from recent heat events, both total CDD or HSI and CDD or HSI anomalies, had a direct influence over respondents' perceptions of heat wave health risks. There are significant temporal effects, however, as indicated by the variables for survey wave participation. For both personal and community health risk perceptions, survey participation in the month of October versus November increases the odds of perceived health risks from heat waves. Thus, there may be a recency effect of summer heat on perceptions of heat waves. Finally, the random effect of climate division is not significantly predictive of heat wave health risk perceptions in any of the models tested. While it is not a significant predictor, the inclusion of climate division as a level in a multilevel model did help to ensure that the effects from the geographically based CDD and HSI variables, as well as the vulnerability indices, were not biased due to latent spatial clustering of similar responses. Latent spatial clustering in this context refers to the likelihood that individuals in close spatial proximity to each other may tend to respond in similar fashion-a phenomenon also referred to as positive spatial autocorrelation. This can be a problem in prediction models because observations 
are assumed to be independent from one another, and the presence of positive spatial autocorrelation would violate this assumption. Finally, none of the nine Census division dummy variables (simply denoted as "ns" in Table 4 to reduce the visual complexity) predict risk perceptions, and this corresponds with the lack of a second-level effect in climate division as well.

\section{Discussion}

This study contributes to the literature on public climate change and heat wave risk perceptions by integrating individual-level survey data with geographic-level biophysical and social vulnerability data to better understand the combined influences of social, geographic, and physical factors on individuals' perceptions of heat waves. Prior studies have typically taken only one of these approaches, examining sociodemographic predictors alone, combining biophysical and survey data, or investigating the extent of social vulnerability to environmental hazards (Van Liere and Dunlap 1980; Cutter et al. 2003; Hamilton and Keim 2009; Howe et al. 2014; Cutler 2015). This study combines insights from all three approaches to compare and contrast these different influences on public perceptions about the health risks of heat waves. We found that global warming beliefs and political and ideological factors, as well as individual- and geographic-level socioeconomic vulnerabilities, influence individuals' perceptions about the health risks posed by heat waves to themselves and others in their communities.

This study also provides new evidence that climate change concern is related to risk perceptions of related phenomena such as heat waves. This is an important finding because it suggests that the experience of heat wave events can be interpreted through individuals' ideological lenses. Although previous research has highlighted the importance influences of political orientation on climate change risk perceptions (e.g., Hamilton 2011; McCright and Dunlap 2011), this analysis shows that extreme heat events may also become politicized phenomena, affecting individuals' assessments of their own vulnerability to heat. If true, this dynamic should inform efforts to promote awareness about the health consequences of prolonged heat exposure.

The importance of multiple indicators of vulnerability, including household income, educational attainment, racial and ethnic background, and age - all at the individual level-as well as measures of hazards and social vulnerability at the census tract level, in predicting individuals' perceptions of the health risks posed by heat waves to themselves and others in their communities is consistent with the extant literature (Akerlof et al. 2010, 2015; Maibach et al. 2015; Cutler 2016). Individuals living in households with higher incomes perceive less risk from future heat waves, suggesting that higher-income households have greater ability to protect against heat wave events, such as the ability to afford energy-intensive air conditioning over several days, or even having the ability to purchase such appliances or afford homes with air conditioning in the first place (Reid et al. 2009).

Interestingly, income predicts both perceived personal and community health risks, suggesting that household income to some extent also captures residential segregation based on socioeconomic status. In other words, individuals tend to live in neighborhoods alongside others with similar income levels to their own, thus precipitating a feeling of shared context, whether that context is one of relative risk or security. The significant influence of the index of geographically based socioeconomic vulnerability provides additional evidence that perceptions of vulnerability to climaterelated hazards are "emplaced" (Gieryn 2000) along with other related concentrated social inequalities, such as income, wealth, deviance, and other geographically relevant social phenomena. In demonstrating a link between geographically based vulnerability and perceptions of heat wave health risks, this study contributes to a growing body of scholarship about the relationship between characteristics of "place," or geography, and perceived environmental changes, risks, and hazards (Hamilton and Keim 2009; Howe et al. 2013; Goebbert et al. 2012; Howe and Leiserowitz 2013; Howe et al. 2014; Cutler 2016; Shao et al. 2016). Income and education are generally highly correlated at individual and area levels, so it is not surprising that the effect of individual-level educational attainment also significantly predicts perceptions of health risks associated with heat waves. Individuals with lower levels of educational attainment more often perceive risks to their own health and the health of others within their communities from future heat waves. Individuals with higher educational attainment are more likely to work in professional or managerial occupations that do not require them to labor outdoors during extreme heat.

Other potential vulnerabilities such as racial and ethnic background and age that often predict environmental risk perceptions (Klineberg et al. 1998; Greenberg 2005; Akerlof et al. 2015) are significant though less-consistent predictors of risk perceptions. Hispanic and African American respondents are more likely to perceive heat wave health risks to themselves, but not for risks to others in their communities, as compared to white respondents. More reliably, those who identify with any other racial or ethnic background, or two or more racial categories, much more often perceive personal health risks of heat waves for both themselves and others in their 
communities. While this research is unable to disaggregate the "other" racial category, these findings suggest a potentially important new avenue for future research with respect to racial and ethnic differences in the perceptions of risks associated with climate change. Racial and ethnic differences in heat wave perceptions require a deeper investigation than this study is able to provide. Prior research has demonstrated that race and ethnicity matter in terms of vulnerabilities to environmental hazards (Brulle and Pellow 2006; Cutter et al. 2006), but it is less clear how perceptions are shaped within these more vulnerable racial and ethnic minority communities.

While individual-level socioeconomic characteristics predict heat wave health risk perceptions, especially household income, geographically based socioeconomic characteristics also predict individual risk perceptions. Individuals living in census tracts with higher social vulnerability more often perceive health risks to themselves and others in their communities. Not only do individuals who are more socioeconomically vulnerable as indicated by their own incomes perceive more risk to themselves and others in their communities, but the socioeconomic status of those surrounding them also appears to influence their perceptions of these vulnerabilities. This finding indicates that risk perceptions are influenced not just by individual-level, social-psychological processes, but also broader, macrolevel processes involving neighborhood- or community-level dynamics, such as socioeconomic circumstances. Whereas prior research has either assessed aggregate social vulnerabilities of geographic areas to environmental hazards (e.g., Reid et al. 2009) or the effect of individual-level vulnerabilities on risk perceptions (e.g., Bord and O'Connor 1997), this study illustrates the importance of both micro- and macrolevel vulnerabilities.

The results regarding vulnerability and risk perceptions also have important implications for communication and public health campaigns aimed at reducing heat-related mortality and illnesses. In their review of NOAA NWS extreme heat warnings methods, Hawkins et al. (2017) find that weather forecasters often report confusion from the inconsistent heat products from NWS and inflexibility with respect to local conditions and impacts. However, given regional variability of climate and the heterogeneity of social, environmental, and infrastructural circumstances across the United States, Hawkins and colleagues note that a national standardization of heat warnings and communications would be "unfeasible and inappropriate" (Hawkins et al. 2017). They do note, however, that the NWS has undertaken efforts to collaborate with local health departments and officials to emphasize important heatrelated health issues and local context (i.e., urban heat island effect) in extreme heat warnings to the general public. The results of our study have implications for efforts such as these by policy makers and stakeholders who are concerned with the public health risks of heat waves. Evidence from our study can be used to inform policy approaches to the communication of heat hazards, specifically that communication strategies should take into consideration the role of individual- and geographically based vulnerabilities, as well as political attitudes about heat and climate change, in shaping perceptions of heat wave health impacts. These insights can help improve the design of communication strategies to increase awareness about the health consequences of heat exposure.

In addition to the consideration of political ideology, climate change beliefs, and social and economic vulnerability, this study incorporated multiple measures of what might be considered the "felt impacts" of heat or heat wave events. By geolocating survey respondents and integrating CDD and HSI data into statistical models as fixed effects of heat incidence and severity, this study assessed the extent to which the direct, experienced impacts of extreme heat might influence individuals' evaluations of the health risks. Contrary to the fourth hypothesized relationship, no evidence of a direct link between these measures of the felt impacts of heat and perceptions of heat wave health risks was found. The lack of any influence on risk perceptions from measures of actual exposure underscores the need for more research on the most appropriate measures of exposure to weather events and other climate-related phenomena. It may be the case that certain physical environmental indicators can illuminate how individuals experience such phenomena, but it may also be possible that such an effect cannot be reliably captured by any particular measure of climate-related impacts, and as such a more comprehensive index of multiple indicators might be worth exploring. It may also be the case that our measures of "felt impacts" do not account for possible individual-level variability that could be captured by measures at higher resolutions (e.g., more localized effects than the climate division is able to provide).

Additionally, more in-depth survey work, or perhaps ethnographic field work and case studies, could identify cultural or other geographically dependent social indicators of risk perceptions. Alternatively, such work could also uncover important geographically specific, sociocultural, and economic factors that constrain risk perceptions among individuals living in the warmest parts of the South, Midwest, or West, or perhaps in the Northeast, where the greatest mismatch between perceptions and actual incidence of heat events may soon develop due to a changing climate. 
This study provides evidence that Americans' perceptions of heat wave risks are substantially shaped by ideological predispositions and beliefs about the reality of global warming but are also linked to their own personal socioeconomic characteristics and the socioeconomic structure of the places in which they live. As the climate changes and the impacts of severe weatherrelated events increase, ideological influences and socioeconomic vulnerabilities will be crucial to understand in order to develop the most effective communication strategies about the risks posed by a warming planet.

Acknowledgments. This research utilizes data from the Climate Change in the American Mind surveys, conducted by the Yale Program on Climate Change Communication and the George Mason University Center for Climate Change Communication. Survey data collection was funded by 11th Hour Project, the Energy Foundation, the Grantham Foundation, the MacArthur Foundation, and the V.K. Rasmussen Foundation. This research was also supported by the National Science Foundation Decision, Risk, and Management Sciences program (SES-1459903).

\section{REFERENCES}

Abrahamson, V., J. Wolf, I. Lorenzoni, B. Fenn, S. Kovats, P. Wilkinson, W. N. Adger, and R. Raine, 2009: Perceptions of heatwave risks to health: Interview-based study of older people in London and Norwich, UK. J. Public Health, 31, 119 126, https://doi.org/10.1093/pubmed/fdn102.

Akerlof, K. L., and Coauthors, 2010: Public perceptions of climate change as a human health risk: Surveys of the United States, Canada and Malta. Int. J. Environ. Res. Public Health, 7, 25592606, https://doi.org/10.3390/ijerph7062559.

_, P. L. Delamater, C. R. Boules, C. R. Upperman, and C. S. Mitchell, 2015: Vulnerable populations perceive their health as at risk from climate change. Int. J. Environ. Res. Public Health, 12, 15 419-15 433, https://doi.org/10.3390/ijerph121214994.

Bolin, B., and L. C. Kurtz, 2018: Race, class, ethnicity, and disaster vulnerability. Handbook of Disaster Research, 2nd ed., H. Rodriguez, W. Donner, and J. Trainor, Eds., Springer, 181203.

Bord, R. J., and R. E. O'Connor, 1997: The gender gap in environmental attitudes: The case of perceived vulnerability to risk. Soc. Sci. Quart., 78, 830-840.

Borden, K. A., and S. L. Cutter, 2008: Spatial patterns of natural hazards mortality in the United States. Int. J. Health Geogr., 7, 64, https://doi.org/10.1186/1476-072X-7-64.

Boruff, B. J., and S. L. Cutter, 2007: The environmental vulnerability of Caribbean island nations. Geogr. Rev., 97, 24-45, https://doi.org/10.1111/j.1931-0846.2007.tb00278.x.

_ C. Emrich, and S. L. Cutter, 2005: Erosion hazard vulnerability of US coastal counties. J. Coastal Res., 21, 932-942, https://doi.org/10.2112/04-0172.1.

Brody, S. D., S. Zahran, A. Vedlitz, and H. Grover, 2008: Examining the relationship between physical vulnerability and public perceptions of global climate change in the United
States. Environ. Behav., 40, 72-95, https://doi.org/10.1177/ 0013916506298800.

Brulle, R. J., and D. N. Pellow, 2006: Environmental justice: Human health and environmental inequalities. Annu. Rev. Public Health, 27, 103-124, https://doi.org/10.1146/ annurev.publhealth.27.021405.102124.

—_, J. Carmichael, and J. C. Jenkins, 2012: Shifting public opinion on climate change: An empirical assessment of factors influencing concern over climate change in the U.S., 2002-2010. Climatic Change, 114, 169-188, https://doi.org/ 10.1007/s10584-012-0403-y.

Bullard, R. D., and G. S. Johnson, 2000: Environmentalism and public policy: Environmental justice: Grassroots activism and its impact on public policy decision making. J. Soc. Issues, 56, 555-578, https://doi.org/10.1111/0022-4537.00184.

Chuang, W. C., P. Gober, W. T. Chow, and J. Golden, 2013: Sensitivity to heat: A comparative study of Phoenix, Arizona and Chicago, Illinois (2003-2006). Urban Climate, 5, 1-18, https:// doi.org/10.1016/j.uclim.2013.07.003.

Cutler, M. J., 2015: Seeing and believing: The emergent nature of extreme weather perceptions. Environ. Sociol., 1, 293-303, https://doi.org/10.1080/23251042.2015.1085117.

, 2016: Class, ideology, and severe weather: How the interaction of social and physical factors shape climate change threat perceptions among coastal US residents. Environ. Sociol., 2, 275285, https://doi.org/10.1080/23251042.2016.1210842.

Cutter, S. L., and C. T. Emrich, 2006: Moral hazard, social catastrophe: The changing face of vulnerability along the hurricane coasts. Ann. Amer. Acad. Pol. Soc. Sci., 604, 102-112, https:// doi.org/10.1177/0002716205285515.

- and C. Finch, 2008: Temporal and spatial changes in social vulnerability to natural hazards. Proc. Natl. Acad. Sci. USA, 105, 2301-2306, https://doi.org/10.1073/pnas.0710375105.

—, B. J. Boruff, and W. L. Shirley, 2003: Social vulnerability to environmental hazards. Soc. Sci. Quart., 84, 242-261, https:// doi.org/10.1111/1540-6237.8402002.

, C. T. Emrich, J. T. Mitchell, B. J. Boruff, M. Gall, M. C. Schmidtlein, C. G. Burton, and G. Melton, 2006: The long road home: Race, class, and recovery from Hurricane Katrina. Environment, 48, 8-20, https://doi.org/10.3200/ENVT.48.2.8-20.

, L. Barnes, M. Berry, C. Burton, E. Evans, E. Tate, and J. Webb, 2008: A place-based model for understanding community resilience to natural disasters. Global Environ. Change, 18, 598-606, https://doi.org/10.1016/j.gloenvcha.2008.07.013.

C. G. Burton, and C. T. Emrich, 2010: Disaster resilience indicators for benchmarking baseline conditions. J. Homeland Secur. Emerg. Manage., 7, 51, https://doi.org/10.2202/1547-7355.1732.

Dietz, T., A. Fitzgerald, and R. Shwom, 2005: Environmental values. Annu. Rev. Environ. Resour., 30, 335-372, https:// doi.org/10.1146/annurev.energy.30.050504.144444.

Dunlap, R. E., and K. D. Van Liere, 1984: Commitment to the dominant social paradigm and concern for environmental quality. Soc. Sci. Quart., 65, 1013-1028.

—, and R. J. Brulle, Eds., 2015: Climate Change and Society: Sociological Perspectives. Oxford University Press, 481 pp.

Egan, P. J., and M. Mullin, 2012: Turning personal experience into political attitudes: The effect of local weather on Americans' perceptions about global warming. J. Polit., 74, 796-809, https://doi.org/10.1017/S0022381612000448.

Finucane, M. L., P. Slovic, C. K. Mertz, J. Flynn, and T. A. Satterfield, 2000: Gender, race, and perceived risk: The 'white male' effect. Health Risk Soc., 2, 159-172, https://doi.org/ $10.1080 / 713670162$. 
Gieryn, T. F., 2000: A space for place in sociology. Annu. Rev. Sociol., 26, 463-496, https://doi.org/10.1146/annurev.soc.26.1.463.

Goebbert, K., H. C. Jenkins-Smith, K. Klockow, M. C. Nowlin, and C. L. Silva, 2012: Weather, climate, and worldviews: The sources and consequences of public perceptions of changes in local weather patterns. Wea. Climate Soc., 4, 132-144, https:// doi.org/10.1175/WCAS-D-11-00044.1.

Greenberg, M. R., 2005: Concern about environmental pollution: How much difference do race and ethnicity make? A New Jersey case study. Environ. Health Perspect., 113, 369-374, https://doi.org/10.1289/ehp.7611.

Gronlund, C. J., A. Zanobetti, G. A. Wellenius, J. D. Schwartz, and M. S. O'Neill, 2016: Vulnerability to renal, heat and respiratory hospitalizations during extreme heat among U.S. elderly. Climatic Change, 136, 631-645, https://doi.org/ 10.1007/s10584-016-1638-9.

Guagnano, G. A., and N. Markee, 1995: Regional differences in the sociodemographic determinants of environmental concern. Popul. Environ., 17, 135-149, https://doi.org/10.1007/ BF02208385.

Hamilton, L. C., 2008: Who cares about polar regions? Results from a survey of U.S. public opinion. Arct. Antarct. Alp. Res., 40, 671-678, https://doi.org/10.1657/1523-0430 (07-105)[HAMILTON]2.0.CO;2.

- 2011: Education, politics and opinions about climate change evidence for interaction effects. Climatic Change, 104, 231242, https://doi.org/10.1007/s10584-010-9957-8.

— about climate change. Int. J. Climatol., 29, 2348-2352, https:// doi.org/10.1002/joc. 1930 .

—_ and M. D. Stampone, 2013: Blowin' in the wind: Shortterm weather and belief in anthropogenic climate change. Wea. Climate Soc., 5, 112-119, https://doi.org/10.1175/ WCAS-D-12-00048.1.

, and M. Lemcke-Stampone, 2014: Arctic warming and your weather: Public belief in the connection. Int. J. Climatol., 34, 1723-1728, https://doi.org/10.1002/joc.3796.

, and T. G. Safford, 2015: Environmental views from the coast: Public concern about local to global marine issues. Soc. Nat. Resour., 28, 57-74, https://doi.org/10.1080/08941920.2014.933926. , and K. Saito, 2015: A four-party view of US environmental concern. Environ. Polit., 24, 212-227, https://doi.org/10.1080/ 09644016.2014.976485.

—_ C. R. Colocousis, and C. M. Duncan, 2010: Place effects on environmental views. Rural Sociol., 75, 326-347, https:// doi.org/10.1111/j.1549-0831.2010.00013.x.

— M. J. Cutler, and A. Schaefer, 2012: Public knowledge and concern about polar-region warming. Polar Geogr., 35, 155168, https://doi.org/10.1080/1088937X.2012.684155.

— C. P. Wake, J. Hartter, T. G. Safford, and A. J. Puchlopek, 2016: Flood realities, perceptions and the depth of divisions on climate. Sociology, 50, 913-933, https://doi.org/ $10.1177 \% 2 \mathrm{~F} 0038038516648547$.

Hawkins, M. D., V. Brown, and J. Ferrell, 2017: Assessment of NOAA National Weather Service methods to warn for extreme heat events. Wea. Climate Soc., 9, 5-13, https://doi.org/ 10.1175/WCAS-D-15-0037.1.

Howe, P. D., 2018: Perceptions of seasonal weather are linked to beliefs about global climate change: Evidence from Norway. Climatic Change, 148, 467-480, https://doi.org/10.1007/ s10584-018-2210-6.

— cold winter? The asymmetric effect of beliefs about global warming on perceptions of local climate conditions in the U.S. Global Environ. Change, 23, 1488-1500, https://doi.org/ 10.1016/j.gloenvcha.2013.09.014.

—, E. M. Markowitz, T. M. Lee, C. Y. Ko, and A. Leiserowitz, 2013: Global perceptions of local temperature change. Nat. Climate Change, 3, 352-356, https://doi.org/10.1038/ nclimate1768.

, H. Boudet, A. Leiserowitz, and E. W. Maibach, 2014: Mapping the shadow of experience of extreme weather events. Climatic Change, 127, 381-389, https://doi.org/ 10.1007/s10584-014-1253-6.

IPCC, 2014: Climate Change 2014: Synthesis Report. Cambridge University Press, 151 pp., http://www.ipcc.ch/pdf/assessmentreport/ar5/syr/SYR_AR5_FINAL_full_wcover.pdf.

Johnson, D. P., A. Stanforth, V. Lulla, and G. Luber, 2012: Developing an applied extreme heat vulnerability index utilizing socioeconomic and environmental data. Appl. Geogr., 35, 2331, https://doi.org/10.1016/j.apgeog.2012.04.006.

Jones, R. E., and R. E. Dunlap, 1992: The social bases of environmental concern: Have they changed over time? Rural Sociol., 57, 28-47, https://doi.org/10.1111/j.1549-0831.1992. tb00455.x.

Kahan, D. M., D. Braman, J. Gastil, P. Slovic, and C. K. Mertz, 2007: Culture and identity-protective cognition: Explaining the white-male effect in risk perception. J. Empirical Legal Stud., 4, 465-505, https://doi.org/10.1111/j.17401461.2007.00097.x.

Kasperson, R. E., and K. Dow, 1993: Hazard perception and geography. Behavior and Environment: Psychological and Geographical Approaches, T. Gärling and R. G. Golledge, Eds., Elsevier, 193-222.

Kates, R. W., 1962: Hazard and choice perception in flood plain management. University of Chicago Department of Geography Research Paper 76, 157 pp.

Kitchin, R. M., M. Blades, and R. G. Golledge, 1997: Relations between psychology and geography. Environ. Behav., 29, 554573, https://doi.org/10.1177/001391659702900406.

Klineberg, S. L., M. McKeever, and B. Rothenbach, 1998: Demographic predictors of environmental concern: It does make a difference how it's measured. Soc. Sci. Quart., 79, 734753.

Klinenberg, E., 2015: Heat Wave: A Social Autopsy of Disaster in Chicago. University of Chicago Press, $320 \mathrm{pp}$

Krosnick, J. A., A. L. Holbrook, and P. S. Visser, 2000: The impact of the fall 1997 debate about global warming on American public opinion. Public Understanding Sci., 9, 239-260, https:// doi.org/10.1088/0963-6625/9/3/303.

Leiserowitz, A., 2005: American risk perceptions: Is climate change dangerous? Risk Anal., 25, 1433-1442, https://doi.org/10.1111/ j.1540-6261.2005.00690.x.

- 2006: Climate change risk perception and policy preferences: The role of affect, imagery, and values. Climatic Change, $\mathbf{7 7}$, 45-72, https://doi.org/10.1007/s10584-006-9059-9.

— E. Maibach, C. Roser-Renouf, G. Feinberg, S. Rosenthal, and J. Marlon, 2014: Public perceptions of the health consequences of global warming: October 2014. Yale Program on Climate Change Communication Rep., 29 pp.

,,--- S. Rosenthal, and M. Cutler, 2017: Climate change in the American mind: November 2016. Yale Program on Climate Change Communication Rep., 48 pp.

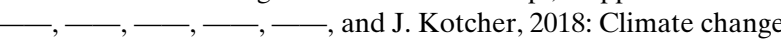
in the American mind: March 2018. Yale Program on Climate Change Communication Rep., 55 pp. 
Lorenzoni, I., and N. F. Pidgeon, 2006: Public views on climate change: European and USA perspectives. Climatic Change, 77, 73-95, https://doi.org/10.1007/s10584-006-9072-z.

Maibach, E. W., J. M. Kreslake, C. Roser-Renouf, S. Rosenthal, G. Feinberg, and A. A. Leiserowitz, 2015: Do Americans understand that global warming is harmful to human health? Evidence from a national survey. Ann. Global Health, 81, 396-409, https://doi.org/10.1016/j.aogh.2015.08.010.

Malka, A., J. A. Krosnick, and G. Langer, 2009: The association of knowledge with concern about global warming: Trusted information sources shape public thinking. Risk Anal., 29, 633647, https://doi.org/10.1111/j.1539-6924.2009.01220.x.

Marlon, J. R., S. van der Linden, P. D. Howe, A. Leiserowitz, S. L. Woo, and K. Broad, 2018: Detecting local environmental change: The role of experience in shaping risk judgments about global warming. J. Risk Res., https://doi.org/10.1080/ 13669877.2018.1430051, in press.

Marquart-Pyatt, S. T., A. M. McCright, T. Dietz, and R. E. Dunlap, 2014: Politics eclipses climate extremes for climate change perceptions. Global Environ. Change, 29, 246-257, https://doi.org/10.1016/j.gloenvcha.2014.10.004.

McCright, A. M., 2010: The effects of gender on climate change knowledge and concern in the American public. Popul. Environ., 32, 66-87, https://doi.org/10.1007/s11111-010-0113-1.

__ 2011: Political orientation moderates Americans' beliefs and concern about climate change. Climatic Change, 104, 243-253, https://doi.org/10.1007/s10584-010-9946-y.

_ - and R. E. Dunlap, 2011: Cool dudes: The denial of climate change among conservative white males in the United States. Global Environ. Change, 21, 1163-1172, https://doi.org/10.1016/ j.gloenvcha.2011.06.003.

_ male effect on worry about environmental problems in the USA. J. Risk Res., 16, 211-226, https://doi.org/10.1080/ 13669877.2012.726242.

— C. Xiao, and R. E. Dunlap, 2014: Political polarization on support for government spending on environmental protection in the USA, 1974-2012. Soc. Sci. Res., 48, 251-260, https://doi.org/10.1016/j.ssresearch.2014.06.008.

Myers, T. A., E. W. Maibach, C. Roser-Renouf, K. Akerlof, and A. A. Leiserowitz, 2013: The relationship between personal experience and belief in the reality of global warming. Nat. Climate Change, 3, 343-347, https://doi.org/ 10.1038/nclimate 1754

Reid, C. E., M. S. O’Neill, C. J. Gronlund, S. J. Brines, D. G. Brown, A. V. Diez-Roux, and J. Schwartz, 2009: Mapping community determinants of heat vulnerability. Environ. Health Perspect., 117, 1730-1736, https://doi.org/10.1289\% 2Fehp.0900683.

Safford, T. G., J. D. Ulrich, and L. C. Hamilton, 2012: Public perceptions of the response to the Deepwater Horizon oil spill: Personal experiences, information sources, and social context. J. Environ. Manage., 113, 31-39, https://doi.org/ 10.1016/j.jenvman.2012.08.022.

Sampson, R. J., 2012: Great American City: Chicago and the Enduring Neighborhood Effect. University of Chicago Press, $534 \mathrm{pp}$.

Schmidtlein, M. C., R. C. Deutsch, W. W. Piegorsch, and S. L. Cutter, 2008: A sensitivity analysis of the social vulnerability index. Risk Anal., 28, 1099-1114, https://doi.org/10.1111/ j.1539-6924.2008.01072.x.

Shao, W., 2016: Are actual weather and perceived weather the same? Understanding perceptions of local weather and their effects on risk perceptions of global warming. J. Risk Res., 19, 722-742, https://doi.org/10.1080/13669877.2014.1003956.

_ - and K. Goidel, 2016: Seeing is believing? An examination of perceptions of local weather conditions and climate change among residents in the U.S. Gulf Coast. Risk Anal., 36, 21362157, https://doi.org/10.1111/risa.12571.

- B. D. Keim, J. C. Garand, and L. C. Hamilton, 2014: Weather, climate, and the economy: Explaining risk perceptions of global warming, 2001-10. Wea. Climate Soc., 6, 119-134, https://doi.org/10.1175/WCAS-D-13-00029.1.

_ J. C. Garand, B. D. Keim, and L. C. Hamilton, 2016: Science, scientists, and local weather: Understanding mass perceptions of global warming. Soc. Sci. Quart., 97, 1023-1057, https://doi.org/10.1111/ssqu.12317.

, S. Xian, N. Lin, and M. J. Small, 2017: A sequential model to link contextual risk, perception and public support for flood adaptation policy. Water Res., 122, 216-225, https://doi.org/ 10.1016/j.watres.2017.05.072.

_- M. Gardezi, and S. Xian, 2018: Examining the effects of objective hurricane risks and community resilience on risk perceptions of hurricanes at the county level in the U.S. Gulf Coast: An innovative approach. Ann. Assoc. Amer. Geogr., 108, 1389-1405, https://doi.org/10.1080/ 24694452.2018 .1426436$.

Shwom, R., A. Dan, and T. Dietz, 2008: The effects of information and state of residence on climate change policy preferences. Climatic Change, 90, 343-358, https://doi.org/ 10.1007/s10584-008-9428-7.

Slovic, P., 1993: Perceptions of environmental hazards: Psychological perspectives. Behavior and Environment: Psychological and Geographical Approaches, T. Gärling and R. G. Golledge, Eds., Elsevier, 223-248.

Spence, A., W. Poortinga, C. Butler, and N. F. Pidgeon, 2011: Perceptions of climate change and willingness to save energy related to flood experience. Nat. Climate Change, 1, 46-49, https://doi.org/10.1038/nclimate1059.

Stern, P. C., and T. Dietz, 1994: The value basis of environmental concern. J. Soc. Issues, 50, 65-84, https://doi.org/10.1111/ j.1540-4560.1994.tb02420.x.

_,$\ldots$, and L. Kalof, 1993: Value orientations, gender, and environmental concern. Environ. Behav., 25, 322-348, https:// doi.org/10.1177/0013916593255002.

Swim, J., S. Clayton, T. Doherty, R. Gifford, G. Howard, J. Reser, P. Stern, and E. Weber, 2009: Psychology and global climate change: Addressing a multifaceted phenomenon and set of challenges. American Psychological Association Rep., 108 pp., http://www.apa.org/science/ about/publications/climate-change-booklet.pdf.

—, P. Stern, T. Doherty, S. Clayton, J. Reser, E. Weber, R. Gifford, and G. Howard, 2011: Psychology's contributions to understanding and addressing global climate change. Amer. Psychol., 66, 241-250, https://doi.org/10.1037/a0023220.

Thomas, D. S., C. Twyman, H. Osbahr, and B. Hewitson, 2007: Adaptation to climate change and variability: Farmer responses to intra-seasonal precipitation trends in South Africa. Climatic Change, 83, 301-322, https://doi.org/10.1007/s10584-006-9205-4.

Van Liere, K. D., and R. E. Dunlap, 1980: The social bases of environmental concern: A review of hypotheses, explanations and empirical evidence. Public Opin. Quart., 44, 181-197, https://doi.org/10.1086/268583.

Weber, E. U., 2010: What shapes perceptions of climate change? Wiley Interdiscip. Rev.: Climate Change, 1, 332-342, https:// doi.org/10.1002/wcc.41. 
White, G. F., 1945: Human adjustment to floods: A geographical approach to the flood problem in the United States. University of Chicago Department of Geography Research Paper 29, 225 pp.

Whitmarsh, L., 2008: Are flood victims more concerned about climate change than other people? The role of direct experience in risk perception and behavioural response. J. Risk Res., 11, 351-374, https://doi.org/10.1080/13669870701552235.

Wilhelmi, O. V., and M. H. Hayden, 2010: Connecting people and place: A new framework for reducing urban vulnerability to extreme heat. Environ. Res. Lett., 5, 014021, https://doi.org/ 10.1088/1748-9326/5/1/014021.
Wolf, J., W. N. Adger, I. Lorenzoni, V. Abrahamson, and R. Raine, 2010: Social capital, individual responses to heat waves and climate change adaptation: An empirical study of two UK cities. Global Environ. Change, 20, 44-52, https://doi.org/ 10.1016/j.gloenvcha.2009.09.004.

Wood, N. J., C. G. Burton, and S. L. Cutter, 2010: Community variations in social vulnerability to Cascadia-related tsunamis in the U.S. Pacific Northwest. Nat. Hazards, 52, 369-389, https://doi.org/10.1007/s11069-009-9376-1.

Zaval, L., E. A. Keenan, E. J. Johnson, and E. U. Weber, 2014: How warm days increase belief in global warming. Nat. Climate Change, 4, 143-147, https://doi.org/10.1038/nclimate2093. 